\title{
A thermogravimetric method for accurate determination of thermodynamic quantities at high temperatures
}

\author{
A. H. VERDONK, J. NEDERMEIJER, and J. W. LAVERMAN \\ Department of Inorganic Chemistry, State University of Utrecht, \\ Croesestraat 77a, Utrecht, The Netherlands
}

(Received 16 April 1974; in revised form 24 April 1975)

\begin{abstract}
A method for the determination of the change in enthalpy, entropy, and specific heat capacity for monovariant heterogeneous equilibria is presented. These quantities are obtained indirectly by measuring the temperature dependence of equilibrium pressures. At a given pressure of the relevant gas the corresponding equilibrium temperature is selected from the continuously recorded temperature cycling around this equilibrium temperature, with the aid of the mass of the condensed phase recorded at the same time. For the equilibrium: $\mathrm{CaCO}_{3}(\mathrm{~s})=\mathrm{CaO}(\mathrm{s})+\mathrm{CO}_{2}(\mathrm{~g})$, from 900 to $1175 \mathrm{~K}$ the results are as follows. For $\Delta_{\mathrm{r}} C_{p}=0: \log _{10}(p / \mathrm{atm})=-8.828 \times 10^{3}(\mathrm{~K} / T)+7.572$, with $\Delta_{\mathrm{r}} H^{\circ}=40.39 \mathrm{kcal}$ th $\mathrm{mol}^{-1}$, and $\Delta_{\mathrm{r}} S^{\circ}=34.64 \mathrm{cal}_{\mathrm{th}} \mathrm{K}^{-1} \mathrm{~mol}^{-1}$. For $\Delta_{\mathrm{r}} C_{p}=13.1 \mathrm{cal}_{\mathrm{th}} \mathrm{K}^{-1} \mathrm{~mol}^{-1}: \log _{10}(p / \mathrm{atm})$ $=-15.227-5.819 \times 10^{3}(\mathrm{~K} / T)+6.596 \log _{10}(T / \mathrm{K})$, with $\Delta_{\mathrm{r}} H^{\circ}(T)=\left\{26.62+13.1 \times 10^{-3}\right.$ $(T / \mathrm{K})\} \mathrm{kcal}_{\mathrm{th}} \mathrm{mol}^{-1}$, and $\Delta_{\mathrm{r}} S^{\circ}(T)=\left\{-56.53+30.16 \log _{10}(T / \mathrm{K})\right\} \mathrm{cal}_{\mathrm{th}} \mathrm{K}^{-1} \mathrm{~mol}^{-1}$.
\end{abstract}

\section{Introduction}

Experimental measuring techniques of thermodynamic constants yield, especially at high temperatures, results which are often not accurate enough for practical purposes and not sufficiently precise for theoretical calculations. ${ }^{(1,2)}$ The proposed method can be used to measure for certain chemical reactions the changes of enthalpy $\left(\Delta_{\mathrm{r}} H\right)$, entropy $\left(\Delta_{\mathrm{r}} S\right)$, and heat capacity $\left(\Delta_{\mathrm{r}} C_{p}\right)$, which have the inter-relations:

in which

$$
\ln K_{\mathrm{a}}=-\Delta_{\mathrm{r}} H^{\circ}(T) / R T+\Delta_{\mathrm{r}} S^{\circ}(T) / R,
$$

$$
K_{\mathrm{a}}=\Pi_{\mathrm{B}}\left(a_{\mathrm{B}}\right)^{r_{\mathrm{B}}} \text {. }
$$

is the equilibrium constant, and

$$
\begin{aligned}
& \left(\partial \Delta_{\mathrm{r}} H / \partial T\right)_{p}=\Delta_{\mathrm{r}} C_{p}, \\
& \left(\partial \Delta_{\mathrm{r}} S / \partial T\right)_{p}=\Delta_{x} C_{p} / T .
\end{aligned}
$$

In the present method the relevant activities in $K_{\mathrm{a}}$ are measured as gaseous pressures. For simplicity in pressure handling we limit ourselves to a monovariant heterogeneous equilibrium involving only one gaseous reactant:

$$
\ln (p / \mathrm{atm})=-\Delta_{\mathrm{r}} H^{\circ}(T) / R T+\Delta_{\mathrm{r}} S^{\circ}(T) / R,
$$

with the pure condensed phases and the pure gaseous phase at $1 \mathrm{~atm}$ pressure as 
standard states. $\dagger$ From measured sets of equilibrium pressure and temperature the sought-for quantities can be calculated from equations (3) to (5).

At the chosen and measured pressure the reactants are subjected to a cyclic temperature program, within narrow temperature limits, around the expected equilibrium temperature. This equilibrium temperature $T_{\text {eq }}$ is selected from a comparison of the synchronously recorded mass and temperature of the condensed phases and iteratively enclosed in subsequent temperature cycles. The most important merit of temperature cycling is the check on the reversibility of the process under study, i.e. the gas-to-condensed phase exchange rate at equilibrium must be much larger than the net reaction rate close to equilibrium. The repeated cycling procedure elucidates the influence of morphological changes in the sample. Its structural and textural history is no longer important, once a reproducible mass pattern has been established.

The thermal dissociation of calcium carbonate (calcite) was selected to check the method because of its reversibility and fast response known from many thorough studies.

\section{Experimental}

In the measuring cell (figures 1 and 2) pressure and flow rate, and temperature, are controlled and measured. The mass of the sample is measured and mass and temperature are simultaneously recorded (figure 3 ).

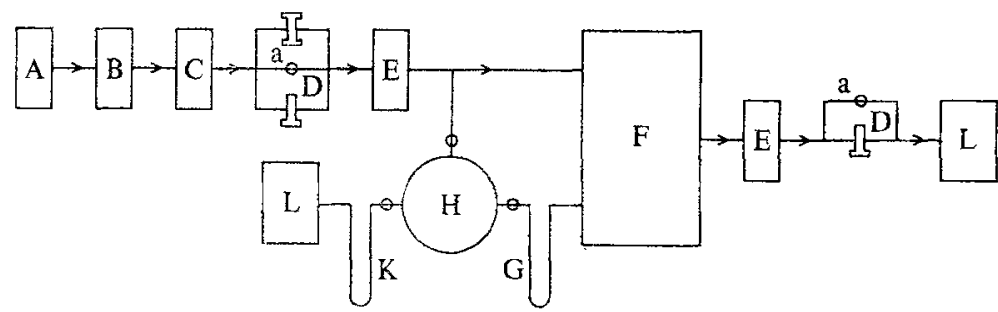

FIGURE 1. Scheme for pressure and flow control and -measurement. A, gas supply; B, gas purification-deoxygenating agent; $C$, gas purification-drying agent; $D$, gas dosage valves, both including a bypass (a); E, rotameter; $\mathrm{F}$, measuring cell, Cahn $\mathrm{RH}$ electrobalance and Dupont $1200^{\circ} \mathrm{C}$ high-temperature d.t.a. furnace with cyclic temperature program; G, oil manometer; $H$, reference pressure in thermostatted volume; $K$, mercury manometer; $L$, vacuum pump.

\section{PRESSURE AND FLOW}

In principle the pressure range should be as wide as possible to get information over a broad temperature range. Our method is limited on the low-pressure side, because it requires pressure and temperature conditions to be identical for reaction interface and gaseous bulk (limit $10^{-2}$ to $10^{-3}$ Torr for a kinetically unhampered process at best). ${ }^{(3,4)}$ The upper limit of the pressure range is reached when some thermodynamic assumptions are no longer valid (compare discussion of "limiting factors" 1 (c) to 1(f)), or when, apart from mechanical limitations, a blank run reveals considerable

$\dagger$ Throughout this paper atm $=101.325 \mathrm{kPa}$; Torr $=(101.325 / 760) \mathrm{kPa} ; \mathrm{cal}_{\mathrm{th}}=4.184 \mathrm{~J}$. 


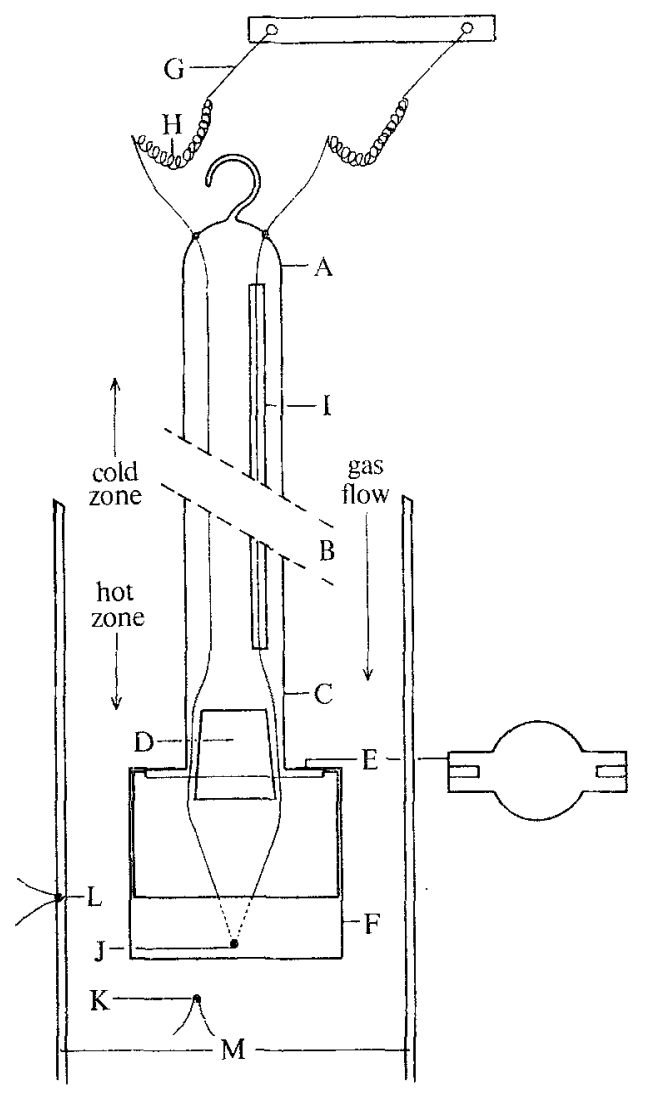

FIGURE 2. Measuring cell with suspension system, sample holder, and thermocouple connexions, Suspension system: external diameter $3 \mathrm{~mm}$, total length approximately $200 \mathrm{~mm}$; A, glass tube; B, glass to quartz seal; C, quartz tube; $D$, quartz plug with notches for thermocouple wires; $E$, quartz wings with notches for sample holder; $\mathrm{E}$, suspension system from below; $\mathrm{F}$, platinum sample holder, internal diameter $7 \mathrm{~mm}$, internal height $2.5 \mathrm{~mm}$; G, thermocouple connexions: platinum wires to plugs on balance support; $\mathrm{H}$, spiralized platinum wires, diameter $10 \mu \mathrm{m} ; \mathrm{I}$, small quartz tube for electrical insulation; $J$, platinum-to-platinum +10 mass per cent rhodium thermocouple in sample; $K$, sensing thermocouple for operating temperature cycle limiting switches; $L$, thermocouple for temperature rate control; $\mathrm{M}$, sintered alumina tube.

deviations of apparent mass. The noise level of the mass signal also has to be minimized at lower ${ }^{(5,6)}$ as well as to higher pressures, being strongly dependent on the geometry of the measuring cell ${ }^{(7)}$ (upper pressure limit $10^{4}$ to $10^{5}$ Torr). For reasons of experimental simplicity we used a carbon dioxide pressure of 10 to 760 Torr and measured it with a manometer.

Gas flow must guarantee the programmed conditions. A minimum flow rate of

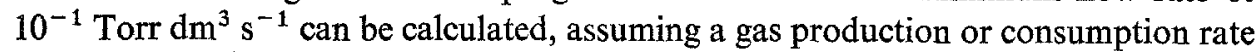
of $20 \mu \mathrm{mol} \mathrm{h}^{-1}$ and accepting 0.1 per cent pressure variation. The maximum flow rate is fixed at about 10 Torr $\mathrm{dm}^{3} \mathrm{~s}^{-1}$ due to the noise level of the mass signal. We used a flow rate of about 0.38 Torr $\mathrm{dm}^{3} \mathrm{~s}^{-1}$ and measured it with rotameters. The flow is regulated by matching gas inlet and outlet to each other in such a way that the 


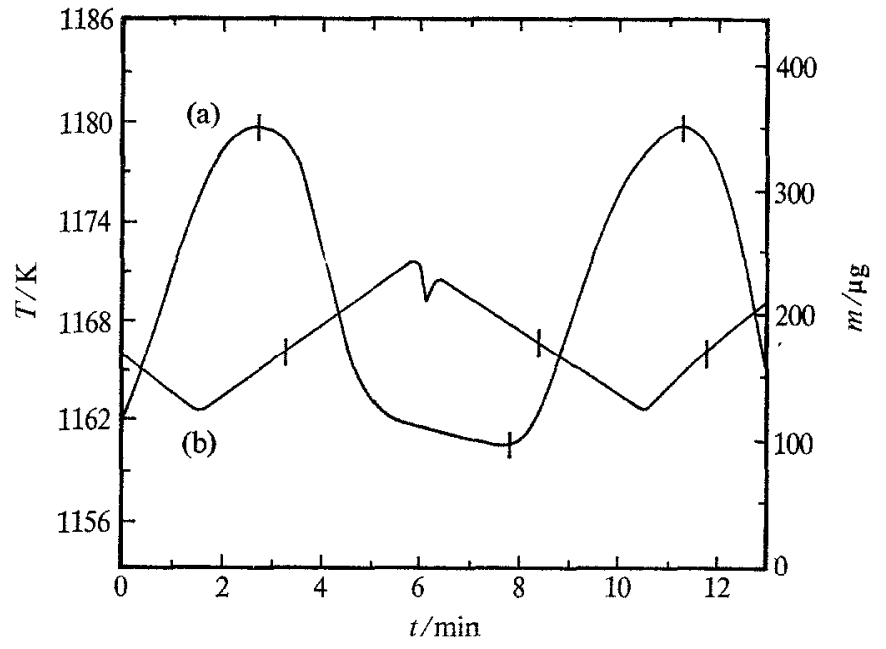

FIGURE 3. A temperature cycle around the equilibrium temperature and the rcsulting mass curve for the reaction: $\mathrm{CaCO}_{3}(\mathrm{~s})=\mathrm{CaO}(\mathrm{s})+\mathrm{CO}_{2}(\mathrm{~g})$, at a $\mathrm{CO}_{2}$ pressure of 757.7 Torr. The disturbance in the temperature pattern is caused by lack of programming when the cycle-limiting switch at the maximum temperature is pushed. It has, as shown, no noticeable effect on the mass signal. The shift of temperature and mass curve with respect to each other is caused by different positions of the two recorder pens on the time axis.

Curve $a$, mass pattern. Curve $b$, temperature pattern.

cell pressure is maintained constant against a previously adjusted constant reference pressure with the aid of an oil manometer. $\dagger$ The sum of the pressures indicated by oil manometer and mercury manometer, the last measuring against vacuum $\left(10^{-2}\right.$ Torr), gives the pressure in the cell with a precision of $10^{-1}$ Torr.

\section{TEMPERATURE}

The temperature range is determined by the chosen pressure range and the $\Delta_{\mathrm{r}} H$ and $\Delta_{\mathrm{r}} S$ values of the process under study. The temperature program is characterized by time function and amplitude of the cycle and by the location of $T_{\text {eq }}$ between the limits. For programmed conditions and still detectable and informative reaction rates, the heating and cooling rate and the amplitude should be as small as the kinetics of the process permits (in this case mostly linear $2 \mathrm{~K} \mathrm{~min}^{-1}$ with amplitude between $5 \mathrm{~K}$ and $15 \mathrm{~K}$ ). The true equilibrium temperature can be iteratively approached by adjusting the amplitude and limits of the temperature cycle in such a way that the arithmetic mean of subsequent maximum and minimum masses is constant, and the difference between the temperature at which the first mass loss is detected $\left(T_{\mathrm{dec}}\right)$, and the temperature at which the first mass gain occurs $\left(T_{\text {rec }}\right)$, is minimal.

The temperature sensor (thermocouple) must be placed at the reaction interface. As a consequence thin electrically highly conducting wires, spiralized perpendicular to the weight force direction in order to minimize the disturbance of the mass signal,

$\uparrow$ Afterwards we turned to a capacitative pressure transducer unit for measuring and control purposes. ${ }^{(8.9)}$ The success of such a sensitive capacitance manometer was demonstrated in static equilibrium measurements at a $\mu \mathrm{g}$ level of sampling by Turcotte $e t a l .^{(10)}$ 
should be used as connexions between the mobile and rigid parts of the balance (figure 2). To obtain a reproducible external geometry of the suspension system at any temperature the electrically isolated thermocouple wires should be mounted in a rigid and therefore voluminous suspension system. The use of a glass quartz tube of the given dimensions with two small openings at the high-temperature side, a sealed low-temperature side, and a small axial surface in the inhomogeneous temperature zone ${ }^{(5)}$ between balance compartment and measuring cell does not raise the noise level of the mass signal. The potential difference of the calibrated thermocouple with a reference couple at $273.16 \mathrm{~K}$ is partially compensated with a stable bias potential from a mercury battery in order to get a more sensitive recorder registration $(1 \mathrm{mV}$ full scale). An ultimate overall precision better than $0.5 \mathrm{~K}$ is reached.

\section{MASS}

A sensitive mass signal, primarily used to determine the equilibrium temperature, is also able to detect other quantities such as the extent and rate of the reaction, deviations from equilibrium conditions, and the variation of pressure and flow. Fortunately, also as a consequence of the narrow temperature limits of the cycle, a blank run does not detect any disturbing effects. Due to the noise level of the mass signal at high temperature, dependent on many experimental factors, ${ }^{(7,11-13)}$ the sensitivity limit is found in the $\mu \mathrm{g}$ range. Theoretically two decades more can be informative. $^{(5)}$ The best accuracy and precision $(2$ to $6 \mu \mathrm{g})$ of the mass signal are reached in the selected pressure range (10 to 760 Torr). The amplitude of the mass cycle can be chosen between 10 and $50 \mu \mathrm{g}$ by iterative adaptation of the temperature program. The mass of the sample is measured by means of a Cahn electrobalance (RH type) and, together with its temperature, recorded on a two-channel Leeds and Northrup instrument (Speedomax XL 682).

\section{SAMPLE}

The condensed phase sample must have a well-defined initial condition with respect to purity, structure, texture (particle size), and amount. ${ }^{(7,14)}$ In view of the characteristics of the cyclic method, the choice of sample pellets (better heat transport) ${ }^{(15)}$ or loose powder (better mass transport) is irrelevant since the sample gets a new reproducible thermal history during subsequent cycles. Nevertheless we used an initially well-defined particle size. As a consequence of our conditions of noise levcl and amplitude of the mass signal the minimum mass of sample should be about $1 \mathrm{mg}$.

\section{PROCEDURE}

The mass of calcium carbonate (calcite, Baker pA, sieved to a particle size of 58 to $69 \mu \mathrm{m}$ ) is chosen between 8 and $15 \mathrm{mg}$ per measurement. After hanging the sample holder on the suspension system and closing the measuring cell, the pressure is reduced to about $10^{-1}$ Torr and the desired gas is let in. This cleaning of the atmosphere is repeated a few times and the ultimately desired pressure is set up. After closing the by-passes the dosage values are iteratively adjusted, so that pressure constancy is reached at the wanted gas flow-rate. To ensure a reproducible prehistory for each measurement a linear heating rate of $5 \mathrm{~K} \mathrm{~min}^{-1}$ is used until the reaction 
has proceeded to the desired extent. Subsequently the appropriate amplitude of the temperature cycle, usually $5 \mathrm{~K} \mathrm{~min}{ }^{-1}$, is adjusted with two mechanical switches on the Dupont 900 Thermoanalyzer. These are operated by the recorder of this instrument registering the temperature signal of thermocouple $\mathrm{K}$ (figure 2) and convert the chosen heating mode into a similar cooling mode and vice versa. Thereafter the heating/cooling rate is lowered to a more acceptable value (mostly $2 \mathrm{~K} \mathrm{~min}^{-1}$ ). The temperatures, $T_{\text {dec }}$ and $T_{\text {rec }}$, as found with the aid of the mass cycles (compare figure 3), are used for calculation together with the relevant pressures.

\section{CALCULATIONS}

For small temperature ranges or limited accuracy of the $(p, T)$ sets, $\Delta_{\mathrm{r}} H^{\circ}(T)$ and $\Delta_{\mathrm{r}} S^{\circ}(T)$ should be taken as temperature independent $\left(\Delta_{\mathrm{r}} C_{p}=0\right)$. By the least-squares method only mean values can be found with equation (5). However, $\Delta_{\mathrm{r}} H^{\circ}(T)$ and $\Delta_{\mathrm{r}} S^{\circ}(T)$ are functions of temperature just as is $\Delta_{\mathrm{r}} C_{p}(T)$. To obtain these thermodynamic functions and their associated standard errors for a wider temperature range and more accurate $(p, T)$ sets, we used the method of Clarke and Glew. ${ }^{(16)}$ They expressed $\Delta_{\mathrm{r}} H^{\circ}(T)$ and $\Delta_{\mathrm{r}} C_{p}(T)$ as a perturbation on the corresponding value at a chosen reference temperature $\theta$, using a Taylor's series expansion, and then rearranged equation (5) to:

$$
\begin{array}{r}
R \ln (p / \mathrm{atm})=-\Delta_{\mathrm{r}} G^{\circ}(\theta) / \theta+\Delta_{\mathrm{r}} H^{\circ}(\theta)\{1 / \theta-1 / T\}+\Delta_{\mathrm{r}} C_{p}(\theta)\{(\theta / T)-1+\ln (T / \theta)\} \\
+(\theta / 2)\left(\mathrm{d} \Delta_{\mathrm{r}} C_{p}(T) / \mathrm{d} T\right)_{\theta}\{(T / \theta)-(\theta / T)-2 \ln (T / \theta)\} .
\end{array}
$$

To obtain the constants in (6) the difference between the right-hand side of this equation for a certain $T_{i}$ and the left-hand side for the corresponding $p_{i}, \uparrow$ is minimized with respect to these constants by the method of least squares. Their values and standard errors at reference temperature $\theta$ are thus calculated using a computer program developed by de Kruif et al. ${ }^{(17)}$ The termination of series (6) depends upon the accuracy of the experimental $(p, T)$ results. For $\Delta_{\mathrm{r}} C_{p}(T)=\Delta_{\mathrm{r}} C_{p}(\theta)$ equation (6) can be simplified to:

$$
\log _{10}(p / \mathrm{atm})=A-B / T+C \log _{10}(T / \mathrm{K})
$$

where

$$
A=\Delta_{\mathrm{r}} S^{\circ}(\theta) / R^{\prime}-\Delta_{\mathrm{r}} C_{p}(\theta) / R^{\prime}-\left\{\Delta_{\mathrm{r}} C_{p}(\theta) / R\right\} \log _{10}(\theta / \mathrm{K}), B=\Delta_{\mathrm{r}} H^{\circ}(\theta) / R^{\prime}-\theta \Delta_{\mathrm{r}} C_{p}(\theta) / R^{\prime},
$$
$C=\Delta_{\mathrm{r}} C_{p}(\theta) / R$, and $R^{\prime}=R \ln 10$. The method is meaningful only when the graph of $\log _{10} p$ against $1 / T$ shows a significant curvature.

\section{Results}

The pattern of the mass function of calcite depends on the pressure and the characteristics of the temperature program. The location of $T_{\text {eq }}$ between the temperature limits determines the extent to which the mean sample mass changes during repeated cycling. $T_{\text {dec }}$ for the first cycle is always found to be higher than for subsequent cycles. In the low-pressure range ( 7 to 15 Torr) it was possible to enforce a repcating but damped mass cycle, only if the sample was first heated a few daK above the ultimate equilibrium temperature. The equilibrium temperatures found for the calcite

$\dagger p_{i}$ and $T_{i}$ form the $i$ th $(p, T)$ set. 
decomposition are not noticeably influenced by the amplitude of the temperature cycle and the extent of the reaction.

The computer program was checked with the experimental pressures and temperatures of Hills, ${ }^{(18)}$ whose detailed results seem very reliable among the abundant literature about the calcite dissociation:

Hills: $\Delta_{\mathrm{r}} H^{\circ}:(39.11 \pm 0.20) \mathrm{kcal}_{\mathrm{th}} \mathrm{mol}^{-1} ; \Delta_{\mathrm{r}} S^{\circ}:(33.1 \pm 0.2) \mathrm{cal}_{\mathrm{th}} \mathrm{mol}^{-1}$.

Our calculation: $\Delta_{\mathrm{r}} H^{\circ}:(39.15 \pm 0.26) \mathrm{kcal}_{\text {th }} \mathrm{mol}^{-1} ; \Delta_{\mathrm{r}} S^{\circ}:(33.26 \pm 0.24)$ $\mathrm{cal}_{\mathrm{th}} \mathrm{K}^{-1} \mathrm{~mol}^{-1}$.

Table 1 contains a series of 42 measured $(p, T)$ sets. The results in tables 2 and 3 show that, even with a small number of measurements, reasonably good thermodynamic values are found. At a given precision of $p$ and $T$ an increasing number of sets obviously increases the precision of the thermodynamic information. Further, a

TABLE 1. Equilibrium measurements of temperature and $\mathrm{CO}_{2}$ pressure for the reaction

$$
\begin{aligned}
\mathrm{CaCO}_{3}(\mathrm{~s})= & \mathrm{CaO}(\mathrm{s})+\mathrm{CO}_{2}(\mathrm{~g}) \cdot(\theta=1073.16 \mathrm{~K})^{\circ} \\
& (\mathrm{Torr}=101.325 / 760 \mathrm{kPa})
\end{aligned}
$$

\begin{tabular}{cccccccccc}
\hline$\frac{T}{\mathrm{~K}}$ & $\frac{p}{\text { Torr }}$ & $\frac{T}{\mathrm{~K}}$ & $\frac{p}{\text { Torr }}$ & $\frac{T}{\mathrm{~K}}$ & $\frac{p}{\text { Torr }}$ & $\frac{T}{\mathrm{~K}}$ & $\frac{p}{\text { Torr }}$ & $\frac{T}{\mathrm{~K}}$ & $\frac{p}{\text { Torr }}$ \\
\hline 1168.7 & 785.7 & 1107.9 & 306.6 & 1072.7 & 167.3 & 1007.2 & 47.8 & 957.2 & 18.1 \\
1165.2 & 757.7 & 1107.7 & 306.5 & 1059.7 & 136.0 & 999.2 & 39.7 & 943.7 & 12.5 \\
1149.7 & 621.1 & 1111.5 & 306.4 & 1054.2 & 120.0 & 991.7 & 34.7 & 938.7 & 12.0 \\
$\mathbf{1 1 3 8 . 2}$ & 500.9 & 1107.7 & 306.5 & 1040.2 & 91.2 & 991.2 & 34.2 & 927.2 & 8.0 \\
1124.0 & 399.9 & 1107.5 & 306.3 & 1021.5 & 66.0 & 972.2 & 24.0 & 922.7 & 8.0 \\
1122.2 & 398.0 & 1097.7 & 259.1 & 1022.7 & 65.7 & 964.7 & 20.1 & 914.2 & 6.7 \\
1111.7 & 325.8 & 1086.0 & 212.1 & 1020.7 & 64.0 & 962.7 & 19.7 & & \\
1109.7 & 322.1 & 1086.7 & 211.2 & 1012.2 & 55.2 & 958.5 & 18.7 & & \\
1109.2 & 306.7 & 1069.7 & 167.7 & 1012.7 & 53.8 & 959.7 & 18.5 & & \\
\hline
\end{tabular}

${ }^{a}$ For thermodynamic data from these $(p, T)$ sets, compare the results for $N=42$ in tables 2 and 3.

comparison can be made between the different ways of handling the characteristic temperatures $T_{\text {dec }}$ and $T_{\text {rec }}$. First it can be assumed that, at the same pressure, $T_{\text {eq }}$ lies between $T_{\text {dec }}$ and $T_{\text {rec }}$. Then the arithmetic mean of $T_{\text {dec }}$ and $T_{\text {rec }}$ will be a good estimate of $T_{\text {eq }}$ (compare table 2: 1 to 3 , and table 3:1 to 3). This agrees with a theoretically based conclusion for a somewhat different temperature program. ${ }^{(19)}$ In a second approach, also used by $\mathrm{Hills}^{(18)}$ in his isothermal equilibrium experiments, $T_{\text {dec }}$ and $T_{\text {rec }}$ at the relevant pressure are handled as if each temperature value is a good estimate of $T_{\text {eq }}$ (compare table $2: 4,5$, and table $3: 4,5$ ). Subsequently it is also informative to handle only the $T_{\text {dec }}$ values as representative for $T_{\text {eq }}$ or conversely $T_{\text {rec }}$ as $T_{\text {eq }}$ (compare table 2:6,7 and 8,9, and table 3:6,7 and 8,9).

The difference between the results from the former two methods is small and the expected decrease of precision is found solely in the approximation $\Delta_{\mathrm{r}} C_{p}=$ constant. The latter two methods give divergent results but the average of each of the thermodynamic values is quite close to the results of the first ones, inherent in the calculation 
TABLE 2. Thermodynamic quantities for the reaction $\mathrm{CaCO}_{3}(\mathrm{~s})=\mathrm{CaO}(\mathrm{s})+\mathrm{CO}_{2}(\mathrm{~g})$ assuming $\Delta_{\mathrm{r}} C_{p}=0$

$\left(\mathrm{cal}_{\mathrm{th}}=4.184 \mathrm{~J}\right)$

\begin{tabular}{|c|c|c|c|c|}
\hline $\begin{array}{l}\text { Series } \\
\text { number }\end{array}$ & $N$ & $\begin{array}{l}\text { Mode of } T \text { data } \\
\text { input }\end{array}$ & $\frac{\Delta_{\mathrm{r}} H^{\circ}}{10^{3} \mathrm{cal}_{\mathrm{th}} \mathrm{mol}^{-1}}$ & $\frac{\Delta_{\mathrm{r}} S^{\circ}}{\mathrm{cal}_{\mathrm{th}} \mathrm{K}^{-1} \mathrm{~mol}^{-1}}$ \\
\hline 1 & 8 & $\left(T_{\mathrm{deg}}+T_{\mathrm{rec}}\right) / 2=T_{\mathrm{eq}}$ & $40.21 \pm 0.68$ & $34.48 \pm 0.63$ \\
\hline 2 & 42 & $\left(T_{\mathrm{dec}}+T_{\mathrm{rec}}\right) / 2=T_{\mathrm{eg}}$ & $40.21 \pm 0.14$ & $34.49 \pm 0.13$ \\
\hline 3 & 344 & $\left(T_{\mathrm{dec}}+T_{\mathrm{rec}}\right) / 2=T_{\mathrm{eq}}$ & $40.39 \pm 0.08$ & $34.64 \pm 0.07$ \\
\hline 4 & 40 & $T_{\mathrm{dec}}=T_{\mathrm{eq}} ; a \quad T_{\mathrm{rec}}=T_{\mathrm{eq}}{ }^{a}$ & $39.15 \pm 0.26$ & $33.26 \pm 0.24$ \\
\hline 5 & 730 & $T_{\mathrm{dec}}=T_{\mathrm{eq}} ; \quad T_{\mathrm{rec}}=T_{\mathrm{eq}}$ & $40.29 \pm 0.08$ & $34.56 \pm 0.07$ \\
\hline 6 & 20 & $T_{\mathrm{dec}}=T_{\mathrm{eq}}{ }^{a}$ & $39.66 \pm 0.36$ & $33.68+0.34$ \\
\hline 7 & 370 & $T_{\mathrm{deo}}=T_{\mathrm{eq}}$ & $40.25 \pm 0.08$ & $34.61 \div 0.07$ \\
\hline 8 & 20 & $T_{\mathrm{rec}}=T_{\mathrm{eq}} a$ & $38.65 \pm 0.23$ & $32.83 \pm 0.21$ \\
\hline 9 & 361 & $T_{r e 0}=T_{\mathrm{eq}}$ & $40.44 \pm 0.10$ & $34.60 \pm 0.09$ \\
\hline
\end{tabular}

${ }^{a}$ Data from Hills. ${ }^{(18)}$

TABLE 3. Thermodynamic quantities for the reaction $\mathrm{CaCO}_{3}(\mathrm{~s})=\mathrm{CaO}(\mathrm{s})+\mathrm{CO}_{2}(\mathrm{~g})$ assuming $\Delta_{\mathrm{r}} C_{p}=$ constant. $(\theta=1073.16 \mathrm{~K})$

$\left(\mathrm{cal}_{\mathrm{th}}=4.184 \mathrm{~J}\right)$

\begin{tabular}{|c|c|c|c|c|c|}
\hline $\begin{array}{l}\text { Series } \\
\text { number }\end{array}$ & $N$ & $\begin{array}{l}\text { Mode of } T \text { data } \\
\text { input }\end{array}$ & $\frac{\Delta_{\mathbf{r}} H^{\circ}(\theta)}{\mathrm{kcal}_{\mathrm{th}} \mathrm{mol}^{-1}}$ & $\frac{\Delta_{\mathrm{r}} S^{\circ}(\theta)}{\mathrm{cal}_{\mathrm{th}} \mathrm{K}^{-1} \mathrm{~mol}^{-1}}$ & $\frac{\Delta_{x} C_{p}}{\mathrm{cal}_{\mathrm{th}} \mathrm{K}^{-1} \mathrm{~mol}^{-1}}$ \\
\hline 1 & 8 & $\left(T_{\mathrm{dec}}+T_{\mathrm{rec}}\right) / 2=T_{\mathrm{eg}}$ & $40.01 \pm 1.53$ & $34.30 \pm 1.43$ & $5.9 \pm 40.5$ \\
\hline 2 & 42 & $\left(T_{\mathrm{dec}}+T_{\mathrm{rec}}\right) / 2=T_{\mathrm{eq}}$ & $40.49 \pm 0.23$ & $34.74 \pm 0.21$ & $6.6 \pm 4.3$ \\
\hline 3 & 338 & $\left(T_{\mathrm{dec}}+T_{\mathrm{rec}}\right) / 2=T_{\mathrm{eq}}$ & $40.68 \pm 0.09$ & $34.89 \pm 0.09$ & $13.3 \pm 2.1$ \\
\hline 4 & 40 & $T_{\mathrm{dec}}=T_{\mathrm{eq}}{ }^{a} \quad T_{\mathrm{rec}}=T_{\mathrm{eq}}{ }^{a}$ & $39.24 \pm 0.28$ & $33.32 \pm 0.26$ & $6.6 \pm 8.4$ \\
\hline 5 & 734 & $T_{\mathrm{tec}}=T_{\mathrm{eq}} ; \quad T_{\mathrm{rec}}=T_{\mathrm{eq}}$ & $40.66 \pm 0.11$ & $34.87 \pm 0.10$ & $12.5 \pm 2.4$ \\
\hline 6 & 20 & $T_{\mathrm{doc}}=T_{\mathrm{eq}}$ & $39.82 \pm 0.39$ & $33.81 \pm 0.36$ & $12.4 \pm 11.6$ \\
\hline 7 & 371 & $T_{\mathrm{dec}}=T_{\mathrm{eq}}$ & $40.26 \pm 0.11$ & $34.61 \pm 0.10$ & $0.9 \pm 2.4$ \\
\hline 8 & 20 & $T_{\mathrm{rec}}=T_{\mathrm{eq}}{ }^{a}$ & $38.66 \pm 0.25$ & $32.84 \pm 0.24$ & $1.1 \pm 7.6$ \\
\hline 9 & 361 & $T_{\mathrm{rec}}=T_{\mathrm{oq}}$ & $41.13 \pm 0.12$ & $35.19 \pm 0.11$ & $23.3 \pm 2.7$ \\
\hline
\end{tabular}

${ }^{a}$ Data from Hills. ${ }^{(18)}$

procedure. However, this divergence supports the compelling requirement of approaching the equilibrium conditions from both sides and thus the use of a cyclic method as recommended here.

Substitution of the most reliable data (compare table $2: 3$ and table $3: 3$ ) in equation (7) yields for the reaction $\mathrm{CaCO}_{3}(\mathrm{~s})=\mathrm{CaO}+\mathrm{CO}_{2}(\mathrm{~g})$ in the tempcrature range 900 to $1175 \mathrm{~K}$ :

For $\Delta_{\mathrm{r}} C_{p}=0: \quad \log _{10}(p / \mathrm{atm})=-8.828 \times 10^{3}(\mathrm{~K} / T)+7.572$,

i.e. $\Delta_{\mathrm{r}} H^{\circ}=40.39 \mathrm{kcal}_{\mathrm{th}} \mathrm{mol}^{-1}$ and $\Delta_{\mathrm{r}} S^{\circ}=34.64 \mathrm{cal}_{\mathrm{th}} \mathrm{K}^{-1} \mathrm{~mol}^{-1}$.

For $\Delta_{\mathrm{r}} C_{p}=13.1 \mathrm{cal}_{\mathrm{th}} \mathrm{K}^{-1} \mathrm{~mol}^{-1}: \quad \log _{10}(p / \mathrm{atm})=-15.227-5.819$

$$
\times 10^{3}(\mathrm{~K} / T)+6.596 \log _{10}(T / \mathrm{K})
$$

i.e. $\Delta_{\mathrm{r}} H^{\circ}(T)=\left\{26.62+13.1 \times 10^{-3}(T / \mathrm{K})\right\} \mathrm{kcal}_{\mathrm{th}} \mathrm{mol}^{-1}$ and $\Delta_{\mathrm{r}} S^{\circ}(T)=\{-56.53$ $\left.+30.16 \log _{10}(T / \mathrm{K})\right\} \mathrm{cal}_{\mathrm{ch}} \mathrm{K}^{-1} \mathrm{~mol}^{-1}$. 
TABLE 4. Thermodynamic quantities for the reaction $\mathrm{CaCO}_{3}(\mathrm{~s})=\mathrm{CaO}(\mathrm{s})+\mathrm{CO}_{2}(\mathrm{~g})$. A comparison of our results with those found by some other authors, either given by them or calculated from their results

$\left(\mathrm{cal}_{\mathrm{th}}=4.184 \mathrm{~J} ; \mathrm{atm}=101.325 \mathrm{kPa}\right)$

\begin{tabular}{|c|c|c|c|c|}
\hline Author & $\frac{\Delta_{\mathrm{r}} H^{\mathrm{o}}(\theta)}{\mathrm{kcal}_{\mathrm{th}} \mathrm{mol}^{-1}}$ & $\frac{\Delta_{\mathrm{r}} S^{\circ}(\theta)}{\mathrm{cal}_{\mathrm{th}} \mathrm{K}^{-1} \mathrm{~mol}^{-1}}$ & $\frac{\Delta_{\mathrm{r}} C_{p}(\theta)}{\mathrm{cal}_{\mathrm{th}} \mathrm{K}^{-1} \mathrm{~mol}^{-1}}$ & $\frac{\theta}{\mathrm{K}}$ \\
\hline Hills $^{(18) a}$ & $39.1 \pm 0.1$ & $33.1 \pm 0.2$ & - & - \\
\hline $\operatorname{Mauras}^{(20) b}$ & 44.63 & 37.67 & -3.97 & 1073 \\
\hline Baker $^{(21) a, c}$ & $38.0 \pm 0.5$ & 32.4 & - & - \\
\hline $\operatorname{Rock}^{(22)}$ & 39.53 & 33.92 & -5.36 & 1000 \\
\hline Landolt-Börnstein ${ }^{(23)}$ & 42.1 & 38.1 & +0.46 & 298 \\
\hline Rossini $i^{(24)}$ & 42.6 & 38.4 & +0.47 & 298 \\
\hline Gorbunov $^{(25)}$ & - & - & +30.94 & 1073 \\
\hline This work ${ }^{a}$ & $40.39 \pm 0.08$ & $34.64 \pm 0.07$ & - & - \\
\hline This work & $40.68=0.09$ & $34.89 \pm 0.09$ & $-13.1 \pm 2.1$ & 1073 \\
\hline
\end{tabular}

${ }^{a}$ Straight line approximation $\left(\Delta_{r} C_{p}(\theta)=0\right)$.

${ }^{b}$ Calculated from equations given by these authors.

- Pressures between 1 and $300 \mathrm{~atm}$.

A comparison of our results in table 4 with those obtained by other authors shows very good agreement for $\Delta_{\mathrm{r}} H^{\circ}$ and $\Delta_{\mathrm{r}} S^{\circ}$, while $\Delta_{\mathrm{r}} C_{p}$ falls within the range of the widely divergent results of others.

\section{Discussion}

The proposed method, mass and temperature measurement at an adjusted pressure, is appropriate for determinations at higher temperatures. ${ }^{(26)}$ Expecially in the temperature range above roughly $800 \mathrm{~K}$, e.m.f. and pressure measurements become competitive in accuracy with high-temperature calorimetric methods. The applicability and accuracy of the latter decrease significantly at higher temperatures (up to $1000 \mathrm{~K}$ : precision 0.5 to 5 per cent, with accuracy a factor 2 to 3 times higher). ${ }^{(27)}$ Moreover in view of their temperature-dependence, measurement of $H^{\circ}, S^{\circ}$, and $C_{p}$, or their reaction values, in the temperature range of interest is necessary. Extrapolation from any other temperature range may be misleading, and the effect might accumulate for the combination to reaction values. This can be demonstrated by substituting $T=298 \mathrm{~K}$ in equation (9) and assuming that our $\Delta_{\mathrm{r}} C_{p}(\theta)$ value is correct. The results differ widely from the tabulated ${ }^{(24)}$ data $\left(\Delta_{\mathrm{r}} H^{\circ}(298 \mathrm{~K})=30.53\right.$ and $42.6 \mathrm{kcal}_{\mathrm{th}} \mathrm{mol}^{-1}$ and $\Delta_{\mathrm{r}} S^{\circ}(298 \mathrm{~K})=18.09$ and $\left.38.4 \mathrm{cal}_{\text {th }} \mathrm{K}^{-1} \mathrm{~mol}^{-1}\right)$.

The proposed dynamic method combines advantages from the other pressuremeasurement methods (for classification of these methods compare Kubaschewski et $a l.):^{(2)}$ control on accuracy and precision of the relevant parameters, their representativity for equilibrium conditions, and the possibility of measurement and control of the gas composition. For, reliable information about pressure and temperature in the sample is possible only at low reproducible reaction rates. ${ }^{(3,30)}$ Otherwise the response of reactant on "thermal stress" gives information which is not characteris- 
tic for the reaction, but only an artifact of the experimental procedure. ${ }^{(14)}$ We stress that approach to equilibrium from both sides is necessary for indirect methods to give chemically relevant results. Moreover, the method is fast and reveals, by its cyclic character, the influence of repetitive measurements.

In principle this method can be applied to obtain thermodynamic as well as overall kinetic information about heterogeneous equilibria with one, or more than one, participating gaseous component. Sublimation, evaporation, gas adsorption, and surface energy studies seem possible, though extension to systems with several components in the condensed phase is less probable due to possible non-equilibrium conditions.

Any periodic temperature function cycling around the equilibrium temperature can be used to enforce repeated decomposition and recombination reactions. The triangular function used thus far is satisfactory for equilibrium studies. A small amplitude sinusoidal signal (likely to cause a similarly shaped mass response) is now under study. From the expected "thermal impedance" response chemical kinetics may probably be split from the other components in the overall kinetics. ${ }^{(36)}$

Our method also combines advantages of some other thermal analysis methods. ${ }^{(3}$, 15,18-20,28-34) The "quasi-isothermal thermogravity" of Paulik and Paulik, ${ }^{(35)}$ using the mass-loss rate to control heating, is also called "quasi-isobaric" due to the use of a "self-generated atmosphere" procedure. This procedure, introduced by Garn and Kessler $^{(37)}$ and reviewed by Newkirk, ${ }^{(38)}$ gives, with its irreproducible premeasurement procedurc, large response time and inaccurately known partial or total pressure and sample temperature, only method-dependent information.

The present method naturally has some limiting factors:

1. Equation (1) can give adequate thermodynamic information only if (a), equilibrium conditions are assumed; (b), if no synchronously occurring parasitic processes are involved; and (c) if no phase transitions occur in the temperature and pressure range of interest; otherwise corrections for phase transitions can be made. For the conversion of $K_{a}$ into pressure, the components in the condensed phase (d), $\uparrow$ are assumed to have thermodynamic potentials which are independent of pressure; and (e) their mutual solubility has to be negligible, and consequently their activities equal to 1 ; and ( $f$ ), the components in the gaseous phase have to be ideal gases. Solid phases often fulfil the demand of mutual insolubility but liquid phases less often. In the case of limited solubility in the condensed phase, pressure measurement at the same solution composition and different temperatures gives the partial enthalpy of solution of the volatile compound.

2. The accuracy and precision of the obtained thermodynamic results are principally determined by the differences between $T_{\text {dec }}, T_{\text {rec }}$, and $T_{\text {eq. }}$. The first two are not only dependent on the applied temperature program, but also on the conversion limiting steps as chemical kinetics, mass- and heat transport, sample crystal structure, -texture and -geometry.

3. The applicability of both pressure and e.m.f. methods is limited, because the chemical reaction to be investigated must be reversible and capable of being 
realized in a heterogeneous condensed phase or gas equilibrium in a galvanic cell in such a way that a relevant pressure or e.m.f. is produced. All methods, either direct (calorimetric) or indirect (activities and e.m.f.) have their own range of applicability and provide supplementary information.

The difference between the actual temperature or pressure at the reaction interface and the corresponding measured value is difficult to estimate. Nevertheless in the temperature range of interest a thermocouple micro-sample combination seems the best of the known possibilities. At higher temperatures other sensors such as pyrometers should be considered. ${ }^{(39)}$ Pressure measurement is not even possible inside the measuring cell and thus the pressure gradient between cell and sensor must either be minimized with a broad and short connexion between both or be known to allow corrections. Pressure correction is in our case not necessary, even when using gas mixtures in the low pressure range $(\approx 10$ Torr), but nevertheless can be simply made. $^{(40,41)} \uparrow$

Moreover, especially in kinetics, complications arise from diffusional effects. When the mechanism of gas production or consumption is hampered the existence of nonequilibrium conditions is conspicuous where other methods meet with difficulties. ${ }^{(43)}$

However as the partial pressure of reactant gas decreases and the supply for the recombination reaction becomes increasingly rate determining, our cyclic method also becomes less sensitive. The problem of capacity and rapid response of the gaseous reactant is a general one in pressure controlling methods. $\ddagger$

We tacitly assumed that the measured pressures are all subject to the same relative error. This assumption is not justified and in future an improved version of the computer program will be used, accounting for the absolute errors in the pressure values. ${ }^{(17)}$ As a consequence the degree of curvature of the curve of $\ln p$ against $1 / T$ and thus $\Delta_{\mathrm{r}} C_{p}$ may not be as reliable as it seems.

In conclusion, the proposed method permits the determination of the reaction enthalpy, entropy, and specific heat capacity for a monovariant heterogeneous condensed phase/gas equilibrium. The repetitive cycling in this dynamic method gives a control on the reaction reversibility and improves the quality of thermodynamic information, since the influence of temperature and sample prehistory is visualized. The authors wish to thank Professor Dr W. van Gool for suggesting the idea of "cycling" to us, and putting this article in order, Mr A. Broersma for his technical assistance, Dr G. H. J. Broers for encouraging discussions and critically reading the manuscript, and Mrs J. Overeem-Zeyl and Miss J. van Randwijk for typing this contribution.

\footnotetext{
$\dagger$ In order to minimize disturbances in the mass signal in the "under convectional" range of pressure $\left(10^{-3}\right.$ to 20 Torr) dilution with inert gas to a total pressure above 20 Torr can be used. ${ }^{(42)}$ Systems containing more than one gas may be subject to errors due to thermal diffusion. These diffusional effects can be eliminated by a sufficient flow rate especially in the narrow parts of the system.

$¥ E$.g. in the study of oxide equilibria $\mathrm{H}_{2}+\mathrm{H}_{2} \mathrm{O}$ or $\mathrm{CO}+\mathrm{CO}_{2}$ equilibrium gas mixtures or for extremely low pressures, an equilibrium mixture of an alkaline earth metal and its oxide. ${ }^{(2)}$ For preparation of gas mixtures see Schwerdftfeger and Turkdogan. ${ }^{(44)}$
} 


\section{REFERENCES}

1. Kulikov, I. S. Thermal dissociation of chemical compounds. Israel Program for Scientific Translations, Jerusalem. 1967, p. 8.

2. Kubaschewski, O.; Evans, E. L. L.; Alcock, C. B. Metallurgical Thermochemistry, 4th edition. Pergamon Press: Oxford. 1967.

3. Rouquerol, J. J. Therm. Anal. 1970, 2, 123.

4. Anderson, P. J.; Horlock, R. F.; Avery, R. G. Proc. Brit. Ceram. Soc. 1965, 3, 33.

5. Robens, E. Vacuum Microbalance Techniques, Vol. 8. Czanderna, A. W.: editor. Plenum Press: New York. 1971, p. 73.

6. Katz, O. M.; Gulbranssen, E. A. Vacuum Microbalance Techniques, Vol, 1. Katz, M.: editor. Plenum Press: New York. 1961, p. 111.

7. Verdonk, A. H. Thesis, State University, Utrecht, The Netherlands. 1970.

8. Zenchelsky, S. T. J. Chem. Ed. 1963, 40, A611; A771; A849.

9. Curran, D. J. J. Chem. Ed. 1969, 46, A401; A465.

10. Turcotte, R. P.; Chikalla, T. D.; Eyring, L. Anal. Chem. 1971, 43, 958.

11. Garn, P. D. Thermoanalytical Methods of Investigation. Academic Press: New York. 1965.

12. Wendlandt, W. W. Thermal Methods of Analysis. Interscience Publishers: New York. 1964.

13. Vacuum Microbalance Techniques, Vols 1 to 8. Plenum Press: New York.

14. Draper, A. L.; Sveum, L. K. Thermochim. Acta 1970, 1, 345.

15. Mauras, H. J. Chim. Phys. 1963, 60, 1419.

16. Clarke, E. C. W.; Glew, D. N. Trans. Faraday Soc. 1966, 62, 539.

17. Kruif, C. G, de, et al. Private communication. (Present address: Department of Chemical Thermodynamics, Trans III, State University of Utrecht, Netherlands.)

18. Hills, A. W. D. Bull. Inst. Mining Metall. 1967, 76C, 241.

19. Proks, I.; Zlatovsky, I. Chem. Zvesti 1969, 23, 620.

20. Mauras, H. Bull. Soc. Chim. Fr. 1959, 16.

21. Baker, E. H. J. Chem. Soc. 1962, 464.

22. Rock, P. A. Chemical Thermodynamics. McMillan Co.: London. 1969.

23. Landolt-Börnstein, Kalorische Zustandsgröszen, Vol. 4. Springer Verlag: Berlin. 1961.

24. Rossini, F. D.; Wagman, D. D.; Evans, W. H.; Levine, S.; Jaffee, J. Selected Values of Chemical Thermodynamic Properties, Natl. Bur. Stand. (U.S.). U.S. Govt. Printing Office: Washington, D.C. 1952.

25. Gorbunov, L. V. Zh. Fiz. Khim. 1965, 39, 6, 1345.

26. Thorn, R. J. Ann. Rev. Phys. Chem. 1966, 17, 83

27. West, E. D.; Westrum, E. F. Experimental Thermodynamics, Vol. 1, Calorimetry of Non-reacting Systems. McCullough, J. P.; Scott, D. W. editors. Butterworth: London. 1968, p. 361.

28. Lorenz, M. R.; Janz, G. J. J. Chem. Ed. 1963, 40, 611.

29. Janz, G. J.; Lorenz, M. R. J. Chem. Eng. Data 1964, 2, 94.

30. Rouquerol, F.; Rouquerol, J. Thermal Analysis, Vol. 1, Wiedemann, H. G.: editor. Birkhäuser Verlag: Basel, 1972, p. 373.

31. Mauras, H. Bull. Soc. Chim. Fr. 1954, 762.

32. Mauras, H. Bull. Soc. Chim. Fr. 1960, 260.

33. Mauras, H. Bull. Soc. Chim. Fr. 1960, 1533.

34. Guenot, J.; Valicon, J. L.; Pannetier, G. Bull. Soc. Chim. Fr. 1967, 3068.

35. Paulik, F.; Paulik, J. Anal. Chim. Acta 1972, 60, 127.

36. To be published.

37. Garn, P. D.; Kessler, J. E. Anal. Chem. 1960, 32, 1563.

38. Newkirk, A. E. Thermochim. Acta 1971,2, 1.

39. Brickwedde, F. G. Temperature, Vol. 3, Part 1. Reinhold Publ. Corp.: New York, 1962.

40. Adamek, J.; Ponec, V. Collec. Czech. Chem. Commun. 1970, 35, 2477.

41. Adamek, J. Collec. Czech. Chem. Commun. 1972, 37, 1069.

42. Czanderna, A. W. Vacuum Microbalance Techniques, Vol. 4. Waters, P. M.: editor. Plenum Press: New York. 1965, p. 69.

43. Grabke, H. J. Z. Phys. Chem. 1972, 78, 211.

44. Schwerdtfeger, K.; Turkdogan, E. T. Techniques of Metais Research, Vol, 4, Bunshah, R. F.: editor. Part 1 Physicochemical Measurements in Metals Research. Rapp, R. A.: editor. Interscience Publishers: New York. 1970, p. 321. 